\title{
THE ACCURACY OF TWO SIMPLIFIED VERSIONS OF THE HALDANE APPARATUS IN THE HANDS OF INEXPERIENCED RESIDENTS
}

\author{
G. D. Blenkarn, M.D., AND H. B. FaIRley, M.B., B.S., F.F.A.R.C.s."
}

The popularuTy of the rebreathing technique for the derivation of arterial carbon dioxide tensions has been assisted by the introduction of simple equipment for the measurement of $\mathrm{CO}_{2}$ concentration in gas samples. It has been suggested that clinically acceptable results can be obtained when equipment of this type is used by relatively inexperienced persons.

The purpose of this study ${ }^{\dagger}$ was to examine the accuracy of two $\mathrm{CO}_{2}$ analysers, Campbell's modification of the Haldane apparatus, ${ }^{1}$ and the Hackney-Collier Rebreathing $P_{\mathrm{CO}_{2}}$ Analyser, ${ }^{\ddagger}$ when these devices were used by anaesthesia residents. The former is stated to be accurate to within \pm 0.1 per cent, and the latter to within \pm 0.25 per cent-both presumably in the hands of experienced technicians.

\section{METHOD}

Ten anaesthesia residents who had not previously used either piece of equipment were given individual instruction in the operation of the apparatus. Instruction periods varied from 15 to 30 minutes and terminated, in each instance, when the trainee was able to achieve reproducibility with a given gas sample. This invariably took longer with the Campbell-Haldane than with the HackneyCollier equipment. Each resident was shown one apparatus first, then asked to analyse six samples of gas containing $\mathrm{CO}_{2}$ in concentrations ranging from 4.11 to 13.48 per cent, in random sequence. The same procedure was then repeated with the second apparatus. Each apparatus was used first by alternate residents.

The six gas samples were analysed before and after the study by an experienced technician, using the Lloyd modification (Lloyd 1958) of the Haldane apparatus.

\section{Results}

The results obtained are shown in Table I. All values were submitted to statistical analysis. Linear regression equations were derived for the comparison of values obtained by each apparatus $(y)$ with the "true" values obtained by the Lloyd-Haldane equipment $(x)$. The two equations $(y=a+b x)$ were:

\section{Campbell-Haldane}

$$
y=-0.317+1.012 x \quad \text { S.E. } b= \pm 0.089,
$$

'Department of Anaesthesia, University of Toronto.

tConducted as part of a familiarization programme in the University of Toronto postgraduate course in anaesthesia.

†Jones Medical Inst. Co. Chicago, Illinois.

Can. Anaes. Soc. J., vol, 13, no. 2, March, 1966 
Hackney-Collier

$$
y=-0.702+1.046 x \quad \text { S.E. } b=0.102 \text {. }
$$

There was no significant difference between the two slopes or between either slope and a correlation of +1.0 . However, results obtained with both pieces of equipment showed a systematic negative bias which was significantly greater $(p<.001)$ in the case of the Hackney-Collier apparatus. Values for this bias $(a)$ were:

Campbell-Haldane

$a=-0.317$ vols. $\%$

Standard Error $= \pm 0.069 \%$

$95 \%$ confidence limits $-0.179 \%$ to $-0.455 \%$,

Hackney-Collier

$a=-0.702$ vols. \%

Standard Error $= \pm 0.090 \%$

$95 \%$ confidence limits $-0.522 \%$ to $-0.882 \%$.

TABLE I

Means and Standard Deviations of 60 Values Obtained with Each Analyser

\begin{tabular}{ccccc}
\hline \hline \multicolumn{2}{c}{ Campbell-Haldane } & & \multicolumn{2}{c}{ Hackney-Collier } \\
\cline { 2 - 2 } $\begin{array}{c}\text { Mean \% } \mathrm{CO}_{2} \\
\mathrm{~N}=10\end{array}$ & S.D. & $\begin{array}{c}\text { "True" value } \\
\left(\% \mathrm{CO}_{2}\right)\end{array}$ & $\begin{array}{c}\text { Mean \% } \mathrm{CO}_{2} \\
\mathrm{~N}=10\end{array}$ & S.D. \\
\hline 4.20 & \pm .394 & 4.11 & 3.68 & \pm .308 \\
5.10 & \pm .373 & 5.73 & 5.25 & \pm .211 \\
6.35 & \pm .380 & 6.65 & 6.17 & \pm .306 \\
7.84 & \pm .360 & 8.05 & 7.73 & \pm .307 \\
10.39 & \pm .320 & 10.56 & 10.37 & \pm .436 \\
13.38 & \pm .257 & 13.48 & 13.39 & \pm .414 \\
\hline
\end{tabular}

\section{Discussion}

Both analysers showed consistent accuracy throughout the range studied relative to each other and to the Lloyd-Haldane values. However, both gave low values throughout, in the hands of inexperienced residents. In the case of the Campbell-Haldane this could be equivalent to $3 \mathrm{~mm}$. $\mathrm{Hg} P_{\mathrm{CO}_{2}}$, whereas figures $6 \mathrm{~mm}$. Hg below "true" values might be obtained with the HackneyCollier machine. These systematic errors would sum with random errors associated with the rebreathing technique itself. The cause of the bias was not immediately obvious, although incomplete absorption or spillage of absorbent into the gas chamber must be considered. Neither was obvious in the case of the Campbell-Haldane. However, the Hackney-Collier apparatus relies on an O-ring to separate absorbent from gas chamber. The instructions state: "The unit requires no washout as the O-ring seal wipes the chamber wall free from excessive solution, the effect of the remainder being negligible at this flow rate." However, in the particular model evaluated, the orifice into the absorption chamber was sufficiently small that it could not be flushed at the prescribed rate. 


\section{SUMMARY}

The accuracy of two simplified versions of the Haldane machine, in the hands of anaesthesia residents, has been evaluated. After a very short period of instruction, residents were able to achieve clinically acceptable accuracy, although both pieces of equipment gave low values. The procedures used with the Hackney-Collier apparatus were easier to learn but gave consistently less accurate results than those obtained with the Campbell modification.

\section{RÉSUMÉ}

On a évalué la précision de deux modèles simplifiés de l'appareil Haldane (Campbell et Hackney-Collier) entre les mains de résidents en anesthésie. Après une courte pratique, les résidents ont pu obtenir des résultats d'une exactitude satisfaisante en clinique, bien que les deux modèles aient donné des volumes plutôt bas. La manière d'utiliser le modèle Hackney-Collier est plus facile à apprendre, mais les résultats obtenus sont en général moins exacts que ceux qui sont fournis par le modele Campbell.

\section{REFERENCE}

1. CAMpbeil, E. J. M. Brit. M. J. 1: 457 (1960). 